\title{
A Platform Business Model for Collaborative Additive Manufacturing
}

\author{
Chiara Freichel \\ University of Wuerzburg \\ chiara.freichel \\ @ uni-wuerzburg.de
}

\author{
Adrian Hofmann \\ University of Wuerzburg \\ adrian.hofmann \\ @ uni-wuerzburg.de
}

\author{
Isabel Ernst \\ University of Wuerzburg \\ IsabelErnst@gmx.net
}

\author{
Axel Winkelmann \\ University of Wuerzburg \\ axel.winkelmann \\ @uni-wuerzburg.de
}

\begin{abstract}
Modern manufacturing is caught in a trade-off between maximizing efficiency and staying flexible in dynamic markets. Inter-organizational sharing of manufacturing capacities on a digital marketplace could contribute to gain flexibility, reduce cost and capital employed as well as provide further business opportunities. Although current research has already prepared the ground for its technical conceptualization, research on such a marketplace's implementation in a business model is scarce. However, since an efficient matching of supply and demand requires a sufficient number of platform users, attracting corporate customers with a suitable business model is crucial. The present research aims to address this problem by developing and evaluating a business model for a marketplace provider, illustrated for the case of additive manufacturing.
\end{abstract}

\section{Introduction}

While simultaneously maintaining the flexibility to react to changing market conditions and customer demands, modern manufacturing strives to maximize efficiency and cutting costs along the supply chain. The efficient coordination in a digital marketplace for manufacturing capacities is subject to the present research. While current research has mainly focused on technical concepts, business models have not yet been explored in detail. Capacity management is a major challenge for manufacturing companies. Uncertainty regarding future demands often results in either over-capacities or shortages [1]. Hence, a collaborative usage of manufacturing capacities provides a solution to react flexibly to changes in demand, supplier failures, and machine break-downs [1].

Traditionally, such collaborative sharing of manufacturing capacities has been difficult since highly specialized machine tools inhibit a simple matching of manufacturing jobs to partners' free capacities [1]. However, with the emergence of additive manufacturing (AM) technologies, custom products can now be produced directly from a 3D computer model, which makes AM suitable for the practical realization of a marketplace. This completely digitized production enables seamless integration of the marketplace into the IT and production infrastructure, disrupting current business models.

Research still lacks an in-depth understanding of configurations of this specific category of marketplace business model. Previous research primarily focused on marketplaces in traditional industry settings, rather than disruptive new business models [2, 3, 4]. Existing relevant literature for digital B2B marketplace business models' design is therefore highly fragmented into different research streams. What is missing is a consolidation of the streams from a holistic business model perspective, allowing the design of innovative marketplaces business models, which consider specifics within an inter-organizational setting.

Overall, to address the given problem set and develop a suitable business model for implementing the concept of a marketplace for AM capacities in practice, the present study seeks to answer the following research questions (RQ):

RQ1: How can we build a theory-based design framework for B2B marketplace business models using a holistic perspective?

RQ2: How can a reference business model for sharing AM capacities be derived from this framework?

To answer the research questions, we first provide an overview of prior research and related work, followed by our methodology description. In Section 4, we present the developed framework and a short case study to demonstrate the framework in Section 5. From there, we develop a reference business model for sharing AM capacities. Finally, we conclude with an outlook for future research. 


\section{Fundamentals and Related Work}

Due to its interdisciplinary nature, the design of a business model for sharing AM capacities requires elaborating conceptual fundamentals from two different research areas. First, the fundamentals for business models, and second, for sharing AM capacities.

We follow the notion of Teece [5, p. 172] who defines a business model as the "[...] design or architecture of the value creation, delivery and capture mechanisms" of a firm. It thus explains the underlying logic of a business along the three dimensions value creation, value delivery, and value capture. The most famous taxonomy in research and practice is the so-called Business Model Canvas [6]. Due to its broad applicability, specific design elements have to be taken into account for platform business models, which influence generic components or even go beyond their initial considerations [7]. Several authors, therefore, developed specific platform design frameworks [4], components [7], pattern dimensions or key attributes [2] to facilitate the analysis and ideation of such platform business models. Goyal et al. [8] presents a literature review on business model development, which leads to further related work. Additionally, Sanchez-Cartas and Leon [9] provide an excellent overview of literature related to multi-sided markets and platform economy. Nevertheless, there is no holistic business model design framework with a particular focus on digital B2B marketplaces.

With the emergence of sharing activities at an inter-organizational level, the concept of sharing economy becomes increasingly relevant in the B2B sector [10]. The possibility of a digital platform for sharing production capacities becomes evident. For instance, Schmitt et al. [11] introduce the idea of a capacity marketplace for sharing production resources. Production processes of collaboration partners could permanently integrate networks of enterprises by connecting their production planning. If integrated into the production process, higher machine utilization at an intra- and inter-enterprise level and, therefore, higher sales can be realized [11]. Further research approaches aim to design such a platform for exchanging production capacities. In previous work, we conceptualized a marketplace implemented as a central platform that can automatically match products with production processes and, hence, supply and demand [12]. Stein et al. [1] further develop and evaluate a prototype for this market-based coordination of AM capacities, allowing real-time decisions and, therefore, instant feedback to customers. As they suggest, AM is especially suitable for matching production capacities by allowing the needed flexibility and scalability. In conclusion, the current concepts have to be extended to a business model dimension.

\section{Methodology}

Since new business models constitute an artifact for a managerial problem, the design science research approach is suitable for the present research. For instance, Tura et al. [4] demonstrate this approach's applicability in a platform context.

We follow the guidelines of design science research introduced by Hevner et al. [13] and the research process, as suggested by Peffers et al. [14]. The artifact to be designed is a suitable business model for the practical (business) implementation of the (technical) concept of a marketplace for AM capacities.

For the design and development of the artifact, we first developed a theory-based design framework for B2B marketplace business models by consolidating research on e-marketplaces and multi-sided platform business models to ensure a robust theoretical foundation for the artifact design. To ensure the framework's practical relevance and applicability, we conducted a case study on two existing marketplace solutions in Section 5. We decided on qualitative interviews for the case study, which provides the needed depth and exploration $[15,16]$. The questions of the semi-structured expert interview were structured along the theory-based design framework and held via phone. The interview was recorded for data processing, and the audio file was transcribed literally, whereby syntax was corrected and fillers deleted. For content analysis, we assigned substantive statements to categories [15].

For the demonstration of the artifact, we present a reference model with the three dimensions value delivery, value creation and value capture in Section 6.

For the final step in the design science process, the artifact must be tested and evaluated. A customer-centric, quantitative approach is highly recommended to evaluate business models [17]. Due to this evaluation's high impact and complexity, this step will be presented in future work.

\section{A Business Model Design Framework for Digital B2B Marketplaces}

To build a business model design framework for digital B2B marketplaces, we extend existing frameworks by key elements for digital B2B marketplaces. We structure the model along the three business model dimensions: value delivery, value creation, and value capture [2]. 
Table 1. Theory-based Design Framework for Digital B2B Marketplace Business Models

\begin{tabular}{|c|c|c|}
\hline Dimensions \& Elements & Design Decision & Literature Base \\
\hline \multicolumn{3}{|l|}{ Value Delivery } \\
\hline \multirow[t]{4}{*}{ Service Bundle } & Range of services: & \multirow[t]{4}{*}[4,2,3,18,19]{} \\
\hline & Transaction-related; facilitation services; value-added services & \\
\hline & Connected Value Proposition: & \\
\hline & E.g. cost advantage vs. collaboration \& transparency in SCM & \\
\hline \multirow[t]{6}{*}{ Customer Segments } & $\begin{array}{l}\text { Market scope: } \\
\text { vertical vs. horizontal markets }\end{array}$ & \multirow[t]{6}{*}{$\begin{array}{l}{[4,2,19,20,21,} \\
22,23]\end{array}$} \\
\hline & Neutrality and Ownership: & \\
\hline & Neutral vs. biased towards sellers or buyers; & \\
\hline & Third-party owned vs. buyer or supplier-owned & \\
\hline & Openness: & \\
\hline & Level of openness in terms of access and control & \\
\hline \multicolumn{3}{|l|}{ Value Creation } \\
\hline \multirow[t]{5}{*}{ Market Mechanisms } & $\begin{array}{l}\text { E-cataloging: } \\
\text { Public vs. private }\end{array}$ & \multirow{5}{*}{$\begin{array}{l}{[3,2,19,24,25,} \\
26]\end{array}$} \\
\hline & Price discovery mechanisms: & \\
\hline & $\begin{array}{l}\text { Pre-fixed prices (set by buyers / sellers / platform provider) vs. dynamic pricing (auctions / } \\
\text { negotiations; private vs. public) }\end{array}$ & \\
\hline & Smart market mechanisms: & \\
\hline & Supporting pricing and/or matching with computational intelligence & \\
\hline \multirow{6}{*}{$\begin{array}{l}\text { Quality Management } \\
\text { \& Governance }\end{array}$} & Quality management and certification mechanisms: & \multirow[t]{6}{*}[4,27,28,29,30]{} \\
\hline & Ex-ante vs. ex-post; soft vs. hard mechanisms; centralized vs. decentralized & \\
\hline & Feedback mechanisms: & \\
\hline & Reviews by participants vs. provider; numerical vs. text comments & \\
\hline & Platform governance: & \\
\hline & Common rules, practices, laws; access restriction or refuse & \\
\hline \multirow[t]{6}{*}{ Platform Technology } & Security features: & \multirow[t]{6}{*}[31,28,3,32]{} \\
\hline & $\begin{array}{l}\text { E.g. authentification checks and access controls; firewalls and intrusion detection systems; } \\
\text { virus protection and encrypted transactions }\end{array}$ & \\
\hline & Level of integration: & \\
\hline & Information-level, customized transaction-level, collaborative level & \\
\hline & Integration with external service providers: & \\
\hline & E.g. financial or logistics service providers & \\
\hline \multicolumn{3}{|l|}{ Value Capture } \\
\hline Revenue Sources & Pricing structure for platform sides: & \multirow[t]{4}{*}[30,23,33,2]{} \\
\hline \multirow[t]{3}{*}{ \& Pricing Structure } & Equal vs. differential pricing & \\
\hline & Key revenue source: & \\
\hline & supply side, demand side or sponsor & \\
\hline \multirow[t]{2}{*}{ Revenue Streams } & Options to charge customers: & \multirow[t]{2}{*}[34,2]{} \\
\hline & $\begin{array}{l}\text { Subscription or membership fees, advertising and permission marketing fees, transaction } \\
\text { fees, posting or order fees, listing or hosting fees, trading information selling fees, } \\
\text { information licensing fees, revenue sharing between business partners, software licensing } \\
\text { fees, private networks sponsorship fees and value-added service fees }\end{array}$ & \\
\hline
\end{tabular}

Value Delivery: The framework's value delivery dimension refers to those business model elements, which deliver value for selected customers [2]. The goal is to offer cost advantages and services targeting improved transparency, collaboration, and integration.

Regarding the offered service bundle, B2B marketplaces create value for their customers by electronically supporting the entire transaction process from information search to price discovery and transaction execution [3]. Through its aggregation role, a B2B marketplace collects information on products from many suppliers and reduces transaction and search costs for customers [3]. Facilitation ranges from internet-based payment to delivery and logistics services [3]. Apart from these mechanisms and services around the transaction process itself, additional value-added services, targeting management needs, can be offered by the marketplace provider [3]. Moreover, platform providers can offer business process support by streamlining workflows and facilitating inter-organizational collaboration.
Decisions on the market scope are one aspect defining the customer segments. Vertical marketplaces are formed around a specific industry to support sourcing goods or services that are primarily specific to this industry [19]. In turn, horizontal marketplaces are formed around products or services and cut across several industries. The different sides of a marketplace are not necessarily equally targeted by a platform provider. Instead, the platform can be biased and owned by buyers or sellers [19]. However, in most cases, a neutral third party can run marketplaces and can equally attract both user sides [19]. According to Eisenmann et al. [20], platforms are open if there are no restrictions on participation regarding development, commercialization, or use. Additionally, any other restrictions have to be reasonable and apply to all participants in the same way. Overall, decisions on platform scope, neutrality, and openness should always be made concerning the needed critical mass of platform users. Nevertheless, it can make sense to launch in a niche market first to establish the platform. 
Value Creation: It is essential to understand that value is co-created on platforms. The provider can not guarantee the benefits (value) of a marketplace since the value is only created when participants collaborate and combine resources [32].

First, market mechanisms need to be specified for the realization of transactions. Marketplaces usually implement an electronic cataloging mechanism. Platform designers can choose between buyer-neutral (public) or customized (private) e-cataloging for unique buyers [3]. Public e-cataloging means that the same products and prices are presented to all potential buyers, whereas private e-cataloging allows market providers to publish different products and price sets for different buyers. Another option is a dynamic price discovery mechanism where prices are negotiated in real-time trading processes, designed as auctions (public) or one-to-one negotiations (private) $[3,19,2]$. In some cases, negotiation mechanisms are also combined with e-cataloging [24]. A third market mechanism category refers to so-called smart market mechanisms where computational intelligence supports decision-making [25]. Here, an algorithm solves the allocation problem for every bid [26] or even directly automate pricing and matching of supply and demand [1].

Besides trading mechanisms, platform governance has to become an essential activity for platform providers [4]. Governance is especially crucial in online marketplaces where effective transactions require the sharing of sensitive financial and corporate data and trading with often previously unknown partners [27]. Unlike other buying situations, trust in e-marketplaces concerns both trust in sellers and the marketplace provider [27]. Therefore, platform providers should prevent quality uncertainty and opportunistic behavior by implementing quality management mechanisms which can either manage behavior before or after it occurs [30]. To this end, platform providers can implement quality certifications, which, in practice, vary in their strictness (soft vs. hard mechanisms) and their centralization (performed by provider vs. participants). Different feedback mechanisms include participants reviewing each other or the platform provider reviewing participants based on standardized metrics [2]. Platform governance also concerns openness in the sense that access to the platform can be restricted or refused if specific criteria are not met [30].

The establishment of trust as a significant challenge has also consequences for the platform technology. Possible security features of marketplace providers are authentication checks and access controls for authorized resources or areas, firewalls and intrusion detection systems, virus protection, and encrypted transactions.
Platform operators have to consider a trade-off between security and ease-of-use [31]. According to Murtaza et al. [31], a significant decision when designing the technological infrastructure relates to the needed level of integration: At the information-level, platform providers link back-end applications of their customers directly to the platform by installing servers. For high transaction rates, customized transaction-level integration might be a better option, where ERP and other systems are directly linked to and integrated with the platform. An even higher level is collaborative integration, which allows marketplace participants to link product design or planning tools and allows collaborative work on products. Which integration level is needed depends on the targeted customer groups' business needs and, consequently, the offered value propositions [31]. Specialized know-how of external service providers can help streamline transaction processes for integrated financial services as well as delivery and logistics where corporate purchasing processes are highly complex[3].

Value Capture: The value capture dimension describes how profit is captured from the created and delivered value. Charging customers for the intermediation might slow down the crucial user base growth [30]. However, it is necessary to pay for maintenance [33].

When designing pricing structures, marketplace designers have to decide whether to charge both platform sides equally for their service or to subsidize one side. This decision determines which customer groups become the key revenue sources of the marketplace. In reality, most multi-sided markets tend to favor one side of the market, where margins are lower ("subsidy-side") in comparison to the so-called "money-side" [23, 33].

If the platform is attractive enough for the subsidy-side, the money-side is willing to pay for accessing the platform. Consequently, depending on the scenario, the money-side can be either the supply or the demand-side of a marketplace. Furthermore, there exists a third option in so-called sponsor-based business models where a third party pays for the expenses [30].

Besides the pricing structure and key revenue source, appropriate revenue streams have to be designed. Zheng [34] offers a broad overview of possible revenue stream options B2B marketplace providers can choose from (see Table 1), including the advantages and disadvantages of each option. Once again, the best option depends on the overall platform strategy and the service bundle offered. 


\section{Case Study: The Marketplace Business Models by 3YOURMIND GmbH}

The following section aims to achieve the practical relevance and applicability of the artifact. We combine the previously presented theoretical implications with practical insights on business model design and customers' preferences. Therefore, we conducted a case study on 3YOURMIND, an existing marketplace provider for AM capacities. We chose 3YOURMIND as a first use case because the company has extensive knowledge gained in a collaborative research project. For the case study, we used the expert interview results with one 3YOURMIND project manager and secondary data from the corporate website to locate the overall business model portfolio. The business model portfolio entails two different marketplace solutions, which offer different value propositions for two different market segments (Table 2). The solutions are a public marketplace for private and business customers and a private $\mathrm{B} 2 \mathrm{~B}$ marketplace solution.

Value Delivery: The service bundle provided on the public marketplace mainly covers transaction-related and facilitation services. Moreover, a real-time pricing algorithm for sellers supports an individualized but simplified price discovery. Therefore, the related value proposition concentrates on search cost reduction and electronically facilitating the pricing and matching process. Nevertheless, since 3YOURMIND sees itself only as a software provider behind the marketplace, it does not arrange any further logistics or other value-added services. The private marketplace is based on the public marketplace's standard platform and includes almost the same transaction-related and facilitation services as the public marketplace service bundle. Additionally, the private B2B marketplace offers value-added services targeting improved processes in AM. The value created stems from improved intra- and inter-organizational transparency and collaboration.

On the buyer side of the public marketplace, the main customer segment consists of private users. Additionally, some corporate customers use the public platform to balance internal capacity shortages. On the seller side, the leading customer group relates to professional printing offices, ranging from SMEs to global networks. One can only register as either buyer or seller, meaning the two user-sides are officially separated. However, many register for both sides, which indicates that a market need for inter-organizational sharing of AM capacities is given. Regarding the public marketplace's neutrality, the two platform sides seem to have different privileges. In price discovery, for instance, sellers are the ones determining the pricing factors. In contrast, when it comes to 3YOURMIND's revenue model, buyers are the ones being incentivized. 3 YOURMIND considers itself as a neural platform provider. The marketplace is open for buyers, while sellers have to pass through a verification process. The private marketplace covers the same customer segments for buyers as the public marketplace, except for private customers. The suppliers depend on individual buyers, who are the marketplace owners. Thus, 3YOURMIND acts no longer as a third-party platform provider in this scenario. Instead, the software customers use the platform as a direct channel to suppliers.

Value Creation: On both the public and private marketplace, 3YOURMIND uses smart market mechanisms to support the matching of supply and demand, including decision-making and price discovery with computational intelligence. In both cases, after uploading their object file, buyers of manufacturing capacities are suited with a configurator, which facilitates the specification of production and technical requirements for the manufacturing job. On the public marketplace, only eligible offers, including prices, are presented to buyers in an otherwise public e-catalog. On the private marketplace, eligible capacities are manually or automatically transmitted to the platform, with a possible real-time integration. Capacity sellers set the prices on both marketplace types and choose between two price discovery mechanisms: real-time pricing and manual pricing. The real-time pricing option enables sellers to specify their pricing algorithms, automatically calculating prices based on specified product features. For manual pricing, the seller estimates prices based on more complex features such as geometry.

Apart from the technological marketplace design, 3YOURMIND's focus on only delivering the technology and software behind the marketplace has also consequences for quality management and governance. The expert states that 3YOURMIND cannot guarantee quality since they only act as an intermediary. However, 3YOURMIND did have a 5-star-review system before, which was too costly to maintain. Since customers directly contact manufacturers in case of insufficient quality, 3YOURMIND sees no need for additional quality management mechanisms. Since in the case of private marketplaces, individual software customers are the ones running the platform, quality management and governance are their individual tasks.

The platform technology goal for both the public and the private marketplace of 3 YOURMIND, is to 
Table 2. Marketplace Business Model Portfolio by 3YOURMIND

\begin{tabular}{|c|c|c|}
\hline Dimensions \& Elements & Public Marketplace & Private Marketplace \\
\hline \multicolumn{3}{|l|}{ Value Delivery } \\
\hline Service Bundle & $\begin{array}{l}\text { Electronically facilitating the matching of AM jobs } \\
\text { and service providers, thereby reducing search costs } \\
\text { and making the process as user-friendly as possible }\end{array}$ & $\begin{array}{l}\text { Allowing the establishment of distributed } \\
\text { manufacturing networks by providing access to and } \\
\text { comparing internal and external suppliers' capacities, } \\
\text { thereby increasing intra- and inter-organizational } \\
\text { collaboration and transparency }\end{array}$ \\
\hline Customer Segments & $\begin{array}{l}\text { Neutral third-party owned and open B2C/B2B } \\
\text { marketplace: } \\
\text { - Buyers: majority private users vs. some corporate } \\
\text { customers (middle-sized and larger; various industries) } \\
\text { - Sellers: professional print service providers (from } \\
\text { SMEs to global networks) }\end{array}$ & $\begin{array}{l}\text { Biased, buyer-owned and private B2B marketplaces: } \\
\text { - Buyers (marketplace-owners): middle-sized and } \\
\text { larger; various industries } \\
\text { - Suppliers: vary depending on individual buyer }\end{array}$ \\
\hline \multicolumn{3}{|l|}{ Value Creation } \\
\hline Market Mechanisms & $\begin{array}{l}\text { Smart market mechanisms for improved decision } \\
\text { making and price discovery: } \\
\text { - Configurator facilitates specification of production and } \\
\text { technical requirements } \\
\text { - Public e-catalog presents eligible offers; not based on } \\
\text { real-time capacities } \\
\text { - Sellers set prices based on either automated real-time } \\
\text { or manual pricing }\end{array}$ & $\begin{array}{l}\text { Smart market mechanisms for improved decision } \\
\text { making and price discovery: } \\
\text { - Configurator facilitates specification of production and } \\
\text { technical requirements } \\
\text { - Private e-catalog presents eligible internal and external } \\
\text { (manually or automatically recorded) capacities } \\
\text { - Sellers set prices based on either automated real-time } \\
\text { or manual pricing }\end{array}$ \\
\hline $\begin{array}{l}\text { Quality Management } \\
\text { \& Governance }\end{array}$ & $\begin{array}{l}\text { Focus on platform technology in-stead of leadership } \\
\text { and governance: } \\
\text { - Ex-ante: verification process for sellers } \\
\text { - Ex-post: responsibility for quality assurance and claim } \\
\text { management shifted to sellers; 5-star-review-system } \\
\text { removed }\end{array}$ & $\begin{array}{l}\text { Quality management and governance as individual } \\
\text { software customer's (buyer's) task }\end{array}$ \\
\hline Platform Technology & $\begin{array}{l}\text { High level of integration with internal and partners' } \\
\text { systems: } \\
\text { - Add-ons for CAD tools } \\
\text { - Integrated payment options } \\
\text { - Direct ERP-systems integration } \\
\text { High security standards: } \\
\text { - Platform-sided: transport layer security, server-side } \\
\text { encryption, rigorous security testing, intrusion detection } \\
\text { and active monitoring to protect the sensitive data of } \\
\text { customers } \\
\text { - Provider-sided: integration with high-level security } \\
\text { environments; regularly passing security audits }\end{array}$ & $\begin{array}{l}\text { Standard platform integration: } \\
\text { - Add-ons for CAD tools } \\
\text { - Integrated payment options } \\
\text { - Direct ERP-systems integration } \\
\text { Collaborative integration into software suite: } \\
\text { The level depends on software type (SaaS vs on-premise } \\
\text { installation) and module combination } \\
\text { High security standards: } \\
\text { - Platform-sided: automatic software and security } \\
\text { updates; Transport layer security, server-side } \\
\text { encryption, security testing, intrusion detection } \\
\text { and active monitoring high-level security } \\
\text { - Provider-sided: integration with high } \\
\text { environments; security audits }\end{array}$ \\
\hline \multicolumn{3}{|l|}{ Value Capture } \\
\hline Revenue Sources & Differential pricing approach: & Differential pricing approach: \\
\hline \& Pricing Structure & $\begin{array}{l}\text { - Buyers use the platform for free } \\
\text { - Sellers are the only revenue source }\end{array}$ & $\begin{array}{l}\text { - Sellers use the platform for free } \\
\text { - Buyers are the only revenue source }\end{array}$ \\
\hline Revenue Streams & Fee depending on net sales generated on the platform & Software licensing fee \\
\hline
\end{tabular}

offer a holistic platform with a high level of integration with customers' and partners' systems. For AM, CAD integration is an especially important topic. To this end, 3 YOURMIND offers add-ons for CAD tools with which customers can easily export their files. Multiple payment options are offered to facilitate the payment process, and ERP systems are directly integrated for accounting.

The integration level of the private marketplace is naturally higher due to managing the entire AM process chain. For this purpose, the software provider offers both to deploy the software inside shared SaaS infrastructure or as on-premises installation, including customization to the customer's requirements. To gain the trust of customers, 3YOURMIND puts security at the foundation of its software. It maintains automatic deployments in both SaaS and on-premise environments to provide regular software and security updates. Besides its software, 3 YOURMIND states to integrate with high-level security environments and to pass security audits regularly.

Value Capture: On both marketplace types, 3YOURMIND follows a differential pricing structure approach. On the public marketplace, sellers pose the only revenue stream. They pay a fee, which depends on net sales generated on the platform. Only if sellers successfully sell their capacities, the fee is charged. Buyers, in turn, do not pay for the matching service. Corporate buyers' willingness to pay is demonstrated on the private marketplaces. Here, software suite customers pay a licensing fee for their customized solution. External manufacturing providers connected to the platform do not pay any fee as there is no direct customer relationship to 3YOURMIND. 


\section{A Reference Business Model for Sharing AM Capacities}

Based on the theoretical and practical implications of business model design, gained from literature research and the case study, we finally derived an initial artifact design in the form of a reference business model for sharing AM capacities (see Table 3). This reference business model presents both must-haves and design options. Features like the direct integration of a complete production planning suite on the marketplace and automated matching and allocation of products and machines are design options that only are enabled by AM's digital nature.

Value Delivery: The problem set to be solved refers to searching for a suitable business model for a B2B marketplace for sharing AM capacities. Therefore, service bundle of the platform lies in supporting and facilitating inter-organizational capacity sharing and is a must-have.

Additionally, we found three suitable value proposition options for the service bundle. First, in option A, the marketplace helps buyers reduce search costs by facilitating matching and price discovery while still leaving them freedom of supplier choice. Second, in option B, instead of focusing on cost reduction, the marketplace aims to improve inter-organizational collaboration inside the supply chain by supporting the establishment of preferred buyer-supplier relationships. Third, in option $\mathrm{C}$, the platform focuses on maximizing its efficiency by automating supply and demand matching.

To reach the marketplaces' overall goal, all users must be business customers. From there, we designed the customer segments as follows. For efficiently trading production resources, machines should be homogeneous [11]. However, as manufacturers across different industries apply AM, it allows for sharing resources with heterogeneous partners [12]. Therefore, to ensure the needed critical mass of users, we consider a horizontal marketplace open for all industries applying AM technologies as a must-have. Furthermore, one has to decide whether users can only register as buyers or sellers or participate as both. For efficient matching, participants should be enabled to balance machine utilization under all circumstances [1] flexibly. Consequently, all participants should ideally or at least optionally act as a buyer and a seller. Concerning the needed critical mass, a neutral third-party-owned marketplace generally implicates an expectable higher user base. Therefore, we suggest realizing the marketplace as a neutral third-party-owned platform.
The marketplace can potentially be open to all interested companies or designed as a private platform with only pre-selected sharing partners. Although an open marketplace might lead to a larger user base, building trust as a major concern makes a private marketplace a suitable option. Thus, both options are included in the reference business model.

Value Creation: To create the proposed value for marketplace participants, there exist different suitable design options for market mechanisms. First, capacity buyers should be supported in entering printing jobs and specifying their needs. In a previous study, we demonstrated that several crucial requirements have to be specified for matching AM jobs with free capacities [12]. Therefore, we suggest implementing an input assistant for buyers, similar to the configurator 3 YOURMIND offers on their platforms, as a must-have in business model design.

To match printing jobs with free capacities, we found three different design options. The first option would be a public, neutral e-catalog presenting all matching capacities. This option provides a good overview of sellers' offers and prices, enables one-stop-shopping, and reduces (search) costs [3]. Second, a private, customized e-catalog, which presents different offer sets to different buyers, is suitable. As a result of this, buyers can pre-select manufacturing capacity sellers to develop pre-qualified buyer-supplier relationships [3]. The last option is the automated matching of manufacturing jobs and free capacities [1]. Finally, we detected three suitable price discovery options. In the first option, sellers set prices, either using an automatic pricing algorithm or by manually entering prices. In the second option, the formation of collaborative buyer-supplier-relationships is supported through private negotiations where, similarly to the private e-catalog option, firms pre-select sharing partners. In the last option, price discovery is part of the automated matching as introduced above, so that jobs are accepted or rejected and lastly matched based on buyers' willingness to pay.

Quality management and governance is a critical challenge in building trust. As the case study has shown, decisions on quality management and governance can be traced back to understanding one's role as a marketplace provider. Therefore, we treat a verification process as a must-have for ensuring a basic quality level.

In addition to the verification process, a review system can help build trust in the platform and maintain a certain quality level in the long term. Because its maintenance is costly, we include the two suitable configurations reviews by buyers and reviews by the 
Table 3. Reference Business Model Design

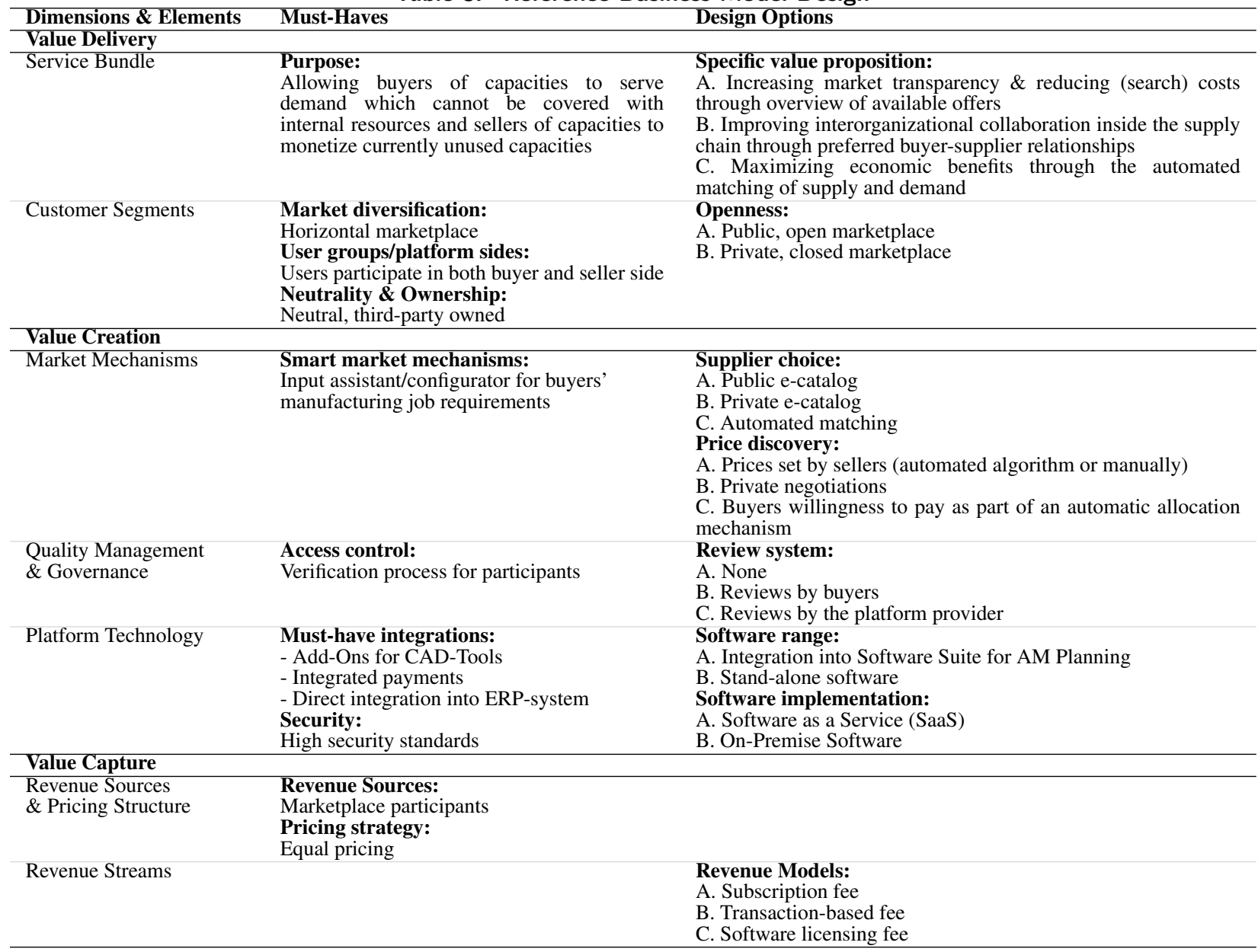

platform provider into the reference business model.

Regarding platform technology, providers have to decide which customers' and partners' systems they integrate into the platform. Therefore, a high level of e-marketplace integration is needed to ensure an efficient sharing of manufacturing capacities. At a basic integration level, we found add-ons for CAD systems are must-haves to enable buyers to share their object files on the marketplace easily. Moreover, to facilitate the transaction process, integrated payment options, and direct ERP integration, are additional must-haves. Security is not only a significant concern on B2B marketplaces in general, but Schmitt et al. [11] highlight information security as one major challenge for a marketplace for sharing production capacities. Therefore, we treat a sufficient security level as a must-have for securing trust in the platform.

To achieve a higher integration level, we found two additional design options. The marketplace can either form a stand-alone software or be integrated into a software bundle with additional AM planning services.
Besides the option to manually enter capacities in a stand-alone software, integration into a software suite for AM planning would allow for automated information sharing on real-time capacity usage. Apart from the software range, also software implementation decides on the level of integration. SaaS allows for a more flexible solution as it usually combines some subscription model and means less initial investment costs. However, an on-premise solution usually allows for a customized implementation based on customers' requirements and better serves integration.

Value Capture: Regarding a suitable revenue model, the design decisions to be made first concern revenue sources and their appropriate pricing structure. The aim is not to achieve cross-side network effects by subsidizing either buyers or sellers since they form no separated user groups. Instead, as capacity matching efficiency increases with a growing total user base, a platform provider for sharing AM capacities should target same-side network effects [1]. 
Consequently, there is no clear "money-side." As the actual participating companies on the platform are not defined yet, we cannot draw any conclusions on customer segments. Therefore, for an initial platform launch, we suggest an equal pricing strategy for all platform users. As already discussed in the case study, AM as a niche market might be too small for an advertising revenue model. Therefore, we do not suggest any third-party revenue sources.

We found three suitable revenue stream options to charge marketplace users concerning the technology options. First, a one-time software-licensing fee forms the classical revenue model for on-premise software. However, a subscription model provides the needed flexibility for a SaaS implementation and, therefore, is much more common [34]. In contrast, the third option of a usage-based fee allows charging users based on their actual platform usage level and scope. This model is riskier for platform providers since incomes are uncertain and may be too low. Nevertheless, it can help grow the user base since no initial investments have to be made, and trying-out the platform is free.

\section{Conclusion}

This study seeks to develop a business model for a digital B2B marketplace for AM capacities by using a design science research approach. Therefore, we designed a theory-based design framework to answer RQ1. We combined this framework with a case study to develop the reference business model and answer RQ2.

On a value delivery dimension, a horizontal, neutral marketplace for exchanging AM capacities allows buyers of capacities to serve demand and sellers of AM capacities to monetize unused capacities. On a value creation dimension, the study's results suggest the implementation of a smart market mechanism. An optional review system should be in place to assure quality verification. On the technology side, integration of CAD, ERP, and payment services allow seamless interaction, while high security standards ensure integrity. In comparison to marketplaces that are not specific to AM capacities, many value-creating features depend on a fully digitized production that is enabled by AM. On a value capture dimension, marketplace participants should pose the only revenue source and an equal pricing strategy should be implemented. However, different revenue models are possible.

This research and its results provide both a scientific and practical contribution. First, from a scientific point of view, it contributes to the emerging research on sharing production capacities. The research complements existing articles (e.g. $[1,12,11])$ on a business model perspective and thus, expands the concept of a marketplace for production capacities on new design elements. Second, the present study also contributes to general research on digital B2B marketplaces. With the theoretically grounded design framework, the study can contribute to a more precise definition of digital B2B business models. Moreover, the chosen design science research approach with its mixed methods of the theory-based design framework and case study is also applicable for research on other B2B marketplace business models. Finally, from a practical point of view, the artifact design provides a good starting point for realizing the concept of a marketplace for sharing AM capacities in practice. Moreover, the theory-based design framework could, similar to taxonomies like the Business Model Canvas, serve as a practical tool for the business model ideation of various types of B2B marketplaces.

However, this research is not without limitations and leaves room for future research. First, as it is exploratory, the final artifact design is influenced by the chosen methods and the derived implications. The theoretical framework needs further testing and development in other marketplace contexts to ensure an empirical validation of its comprehensiveness. Furthermore, the developed artifact must-haves and design options were primarily derived from the case study's implications and are thus highly influenced by 3YOURMIND's business model design. Further case studies of other marketplaces could evaluate the reference business model. Finally, the artifact's evaluation is not part of this paper and could lead to final adjustments of the reference business model.

The present study focused on the particular case of sharing AM capacities. Therefore, the transfer to marketplaces of other types of production capacities should be researched. Future research should explore both the technical concept and suitable business model design for other industries to unlock the potential of sharing production capacities.

\section{Acknowledgements}

This study is based upon work funded by the German Federal Ministry of Education and Research (BMBF) within the program "Innovations for Tomorrow's Production, Services, and Work" (funding number 02K16C100) and implemented by the Project Management Agency Karlsruhe (PTKA).

\section{References}

[1] N. Stein, C. M. Flath, and B. Walter, "Towards Open Production: Designing a Marketplace for 3D-Printing 
Capacities," International Conference on Information Systems, 2019.

[2] K. Täuscher and S. M. Laudien, "Understanding Platform Business Models: A Mixed Methods Study of Marketplaces," European Management Journal, vol. 36, no. 3, pp. 319-329, 2018.

[3] Q. Dai and R. J. Kauffman, "Business Models for Internet-Based B2B Electronic Markets," International Journal of Electronic Commerce, vol. 6, no. 4, pp. 41-72, 2002.

[4] N. Tura, A. Kutvonen, and P. Ritala, "Platform Design Framework: Conceptualisation and Application," Technology Analysis \& Strategic Management, vol. 30, no. 8, pp. 881-894, 2018.

[5] D. J. Teece, "Business Models, Business Strategy and Innovation," Long Range Planning, vol. 43, no. 2-3, pp. 172-194, 2010.

[6] A. Osterwalder and Y. Pigneur, Business model generation: A Handbook for Visionaries, Game Changers, and Challengers. Toronto: Flash Reprod, 2 ed., 2010.

[7] A. Schweiger, J. Nagel, M. Böhm, and H. Krcmar, "Platform business models," in Digital Mobility Platforms and Ecosystems, pp. 66-77, mediaTUM, 2016.

[8] S. Goyal, A. Kapoor, M. Esposito, and B. S. Sergi, "Understanding business model-literature review of concept and trends," International Journal of Competitiveness, vol. 1, no. 2, pp. 99-118, 2017.

[9] J. M. Sanchez-Cartas and G. Leon, "Multisided platforms and markets: A literature review," 2019.

[10] B. Ocicka and G. Wieteska, "Sharing Economy in Logistics and Supply Chain Management," Logforum, vol. 13, no. 2, pp. 183-193, 2017.

[11] R. Schmitt, S. Humphrey, M. Ellerich, and S. Groggert, "Kapazitätsmarkt - Ressourcenhandel für die Produktion: Eine Cloud-basierte Plattform zum unternehmensübergreifenden Austausch von Produktionskapazitäten," Industrie 4.0 Management, vol. 31, no. 4, pp. 30-34, 2015.

[12] C. Freichel, A. Hofmann, M. Fischer, and A. Winkelmann, "Requirements and a Meta Model for Exchanging Additive Manufacturing Capacities," International Conference on Wirtschaftsinformatik, pp. 2-16, 2019.

[13] Hevner, March, Park, and Ram, "Design Science in Information Systems Research," MIS Quarterly, vol. 28, no. 1, pp. 75-105, 2004.

[14] K. Peffers, T. Tuunanen, M. A. Rothenberger, and S. Chatterjee, "A Design Science Research Methodology for Information Systems Research," Journal of Management Information Systems, vol. 24, no. 3, pp. 45-77, 2007.

[15] B. Gillham, The Research Interview. London and New York: Continuum, 2000.

[16] J. Gwee, The Case Writer's Toolkit. Singapore: Palgrave MacMillan, 2018.

[17] J. F. Tesch, M. Lehmbrink, G. Remané, and L. M. Kolbe, "Customer Surveys as a Quantitative Evaluation Tool for Digital BMI," in Business Model Innovation in the Era of the Internet of Things (J. F. Tesch, ed.), pp. 177-208, Cham: Springer International, 2019.
[18] J. P. Bailey and Y. Bakos, "An Exploratory Study of the Emerging Role of Electronic Intermediaries," International Journal of Electronic Commerce, vol. 1, no. 3, pp. 7-20, 1997.

[19] D. Lu and J. Antony, "Implications of B2B Marketplace to Supply Chain Development," The TQM Magazine, vol. 15, no. 3, pp. 173-179, 2003.

[20] T. R. Eisenmann, G. Parker, and M. W. van Alstyne, "Opening Platforms: How, When and Why?," in Platforms, markets and innovation (A. Gawer, ed.), pp. 131-162, Cheltenham, U.K and Northampton, Mass: Edward Elgar, 2009.

[21] K. Boudreau, "Open Platform Strategies and Innovation: Granting Access vs. Devolving Control," Management Science, vol. 56, no. 10, pp. 1849-1872, 2010.

[22] B. Edelman, "How to launch your digital platform," Harvard Business Review, vol. 93, no. 4, pp. 90-97, 2015.

[23] D. S. Evans, "Some empirical aspects of multi-sided platform industries," Review of Network Economics, vol. 2, pp. 1-20, 2003.

[24] B. Lennstrand, M. Frey, and M. Johansen, "Analysing B2B eMarkets - the Impact of Product and Industry Characteristics on Value Creation and Business Strategies," in ITS Asia-Indian Ocean Regional Conference, vol. July 2-3, Perth, Australia: ITS, 2001.

[25] M. Bichler, A. Gupta, and W. Ketter, "Research Commentary - Designing Smart Markets," Information Systems Research, vol. 21, no. 4, pp. 688-699, 2010.

[26] J. Gallien and L. M. Wein, "A Smart Market for Industrial Procurement with Capacity Constraints," Management Science, vol. 51, no. 1, pp. 76-91, 2005.

[27] M.-S. Kim and J.-H. Ahn, "Management of Trust in the E-Marketplace: The Role of the Buyer's Experience in Building Trust," Journal of Information Technology, vol. 22, no. 2, pp. 119-132, 2007.

[28] E. Loukis, D. Spinellis, and A. Katsigiannis, "Barriers to the Adoption of B2B e-Marketplaces by Large Enterprises: Lessons Learned From the Hellenic Aerospace Industry," Information Systems Management, vol. 28, no. 2, pp. 130-146, 2011.

[29] P. A. Pavlou and A. Dimoka, "The Nature and Role of Feedback Text Comments in Online Marketplaces: Implications for Trust Building, Price Premiums, and Seller Differentiation," Information Systems Research, vol. 17, no. 4, pp. 392-414, 2006.

[30] J. Kim, "The Platform Business Model and Business Ecosystem: Quality Management and Revenue Structures," European Planning Studies, vol. 24, no. 12, pp. 2113-2132, 2016.

[31] M. B. Murtaza, V. Gupta, and R. C. Carroll, "E-marketplaces and the Future of Supply Chain Management: Opportunities and Challenges," Business Process Management Journal, vol. 10, no. 3, pp. 325-335, 2004.

[32] S. Standing and C. Standing, "Service Value Exchange in B2B Electronic Marketplaces," Journal of Business \& Industrial Marketing, vol. 30, no. 6, pp. 723-732, 2015.

[33] T. Eisenmann, G. Parker, and M. W. van Alstyne, "Strategies for Two-Sided Markets," Harvard Business Review, vol. 84, no. 10, pp. 92-101, 2006.

[34] W. Zheng, "The Business Models of E-marketplace," Communications of the IIMA, no. 6, pp. 1-18, 2006. 